\title{
What we talk about when we talk about interactivity: Empowerment in public discourse
}

\section{Marguerite Barry and Gavin Doherty}

Trinity College Dublin, Ireland

\begin{abstract}
This study offers new insights into interactivity by examining its association with empowerment in public discourse. Using data from 20 years of newspaper coverage, a mixed methods analysis reveals different 'modes' of interactivity in discourse. Empowerment is the dominant mode of interactivity despite substantial changes in technologies and uses over this time. A content analysis shows that older discourses associate interactivity with specific technologies, while recent discourses use more universal terms. The discourse analysis illustrates the range of empowerment found in different interactive experiences, from basic data access to collaboration across communities, even reaching beyond communication events. The study offers a new model for understanding interactivity and empowerment based on the potential in communications for action, context, strategies and outcomes. This layered and flexible approach has appeal for digital media research and production.
\end{abstract}

\section{Keywords}

Communication model, content analysis, discourse analysis, empowerment, HumanComputer Interaction, human-computer interaction, interactive media, interactivity

\section{Introduction}

Interactivity is integral to digital communications and one of the key terms of new media discourse (McQuail, 2010). Its value hinges on its impact on communication effectiveness

\section{Corresponding author:}

Marguerite Barry, School of Computer Science \& Statistics, Trinity College Dublin, Dublin 2, Ireland.

Email: marguerite.barry@scss.tcd.ie 
and information retention (Heeter, 1989; Koolstra and Bos, 2009), its effects on individuals and social processes (Stromer-Galley, 2004) and how it challenges concepts of authorship, audience and texts (Cover, 2006). But it carries 'a cluster of associated meanings' (Lister et al., 2003) as one of the more 'unsettled issues' in digital media (Reinhard, 2011). Despite academic interest, there is little agreement on how to define or measure interactivity (Barry, 2014; Koolstra and Bos, 2009). However, consensus on its meaning is critical for successful design and evaluation of digital media.

Prior research has focused on defining interactivity and is dominated by studies examining individual users interacting online (Barry, 2012c). Human-Computer Interaction (HCI) theory contributes models and frameworks of interactivity that reflect shifts in the contextual paradigms of digital media use, for example, from individual desktop user to ubiquitous computing (Rogers et al., 2011). However, the continuing proliferation of technologies and layering of paradigms of use demand a more contextually flexible approach to interactivity.

This study draws on Richards' (2006) concerns about the inadequacy of theory in describing the power of interactivity. It aligns with efforts to find a new way of 'thinking about and describing interactivity regardless of its manifested forms' (Lim et al., 2009). It offers a mixed method analysis aimed at describing interactivity by examining how we talk about the concept. Comparing two datasets of Irish and international discourses on the concept, it shows that interactivity is now associated more generally with digital communication rather than with specific technologies as in the past. Multiple representations or 'modes' of interactivity coexist in public discourse, and frequent 'modes' include Aesthetic, Ludological and Pedagogical interactivity. However, Empowerment is the dominant mode across most configurations.

The analysis provides insights into what we talk about when we talk about interactivity. It focuses on how interactivity and empowerment are linked through the actions, context, strategies and outcomes of digital communications. The study produces a new model showing interactivity and empowerment are linked which is of for benefit digital media theory and practice.

\section{Perspectives on interactivity}

Digital media allow users to manipulate content and intervene in its meaning, creating 'interactive' potential (Lister et al., 2003). Thus, early studies identify interactivity as a characteristic of technology, an archaeological approach that emphasises technological developments over uses or effects (Huhtamo, 1999). Early hype around interactivity raised questions about its attributes beyond being a label (Aarseth, 1997; Jensen, 1998; Shultz, 2000). The debate over what makes 'interactive television' actually interactive attracted useful perspectives from marketing and advertising (Holmes, 2004) but fuelled concerns about this 'buzzword' to sell the capacities of technology (Winston, 1998). Later studies turned to the 'cultural and computing' (Manovich, 2003) and the rapid proliferation of technologies with interactive potential (Sundar, 2004). There followed an increase in academic interest, reflecting its growing importance as a research concept (Koolstra and Bos, 2009). A turn to the user placed more emphasis on perception, bringing psychology and semiotics perspectives into play (Newhagen, 2004; Rogers et al., 
2011), along with 'active audience' theory, viewing interactivity as part of wider media 'practice' (Couldry, 2012; Morley, 1993).

Throughout, studies on interactivity have been framed around the search for a single, bounded definition. Interactivity is defined as either (a) a characteristic of the medium (Sundar, 2004), (b) dependent on the context in which messages are exchanged (Rafaeli and Sudweeks, 1997) or (c) 'a perception in users' minds' (Bucy, 2004; McMillan, 2002). The fusion of all three facilitates greater understanding of the subject (Kiousis, 2002), but 'rival camps' emphasise different aspects of its operation (Quiring, 2009). One of the concerns of this study is the effect of competing discourses around interactivity on outcomes in practice.

Methodologies for studying interactivity. Previous studies include theoretical and empirical analyses (Jensen, 1998; Kiousis, 2002; McMillan, 2002; Nash, 2012; Richards, 2006), but online user studies dominate research (e.g. Downes and McMillan, 2000; Hujanen and Pietikainen, 2004; Jensen, 2005; Larsson, 2012; Quiring, 2009; Ziegele et al., 2014) with some offering alternative research contexts (Heath et al., 2005). While offering useful insights into interactivity, findings are narrowly applicable, in light of evidence that digitally literate users have preconceptions and expectations of interactivity which may affect their perception (Sohn and Choi, 2013).

Computer-mediated communication (CMC) studies analyse the 'real artefacts' of communication by focusing on 'interrelatedness of messages' (Rafaeli and Sudweeks, 1997). While constructive, this uses interactivity as a measurement tool and a finding, restricting further application. Further studies use 'interrelatedness' to measure the interactivity of user comments online (Birch and Weitcamp, 2010; Weber, 2014), describing the nature of connections effectively but not interactivity itself. Richards (2006) identifies a 'generative' capacity in interactivity, producing further interactivity beyond the initial event. This plurality is also found where several distinct phenomena in communications are viewed as layered 'interactivities' (Jensen, 2013:184; Reinhard, 2011). However, interactivity now features mostly in research into other media phenomena, for example: why some user commentary in news is 'more interactive than others' (Ziegele et al., 2014); 'interactivity as a strategy' in online documentaries (Nash, 2012); how the spectrum of interactivity relates to the social media platform in use in newsrooms (Canter, 2013). These studies often cite Kiousis' (2002) influential hybrid definition which operationalises interactivity as fusing together technology, context and user perception. This greatly assists research but does not address how interactivity operates either specifically or in layers or how it might be designed or understood within more flexible communication contexts. Such aspects of meaning are not adequately catered for in the academic discourse on interactivity, which remains underdefined.

Problematising interactivity. Despite the volume of research, academic discourse has failed to fully explain interactivity, indicating a 'problematisation', which discourse analysis can address (Howarth, 2000). Jensen (2005) calls for research into the circulation of ideas about interactivity, recognising that '... different notions of interactivity may be ... negotiated between discourses of marketing, public debate and practical design ...' (p. 11). This study uses discourse to widen discussion on interactivity towards 
better understanding, a common goal in discourse analysis (Jorgensen and Phillips, 2002). It examines public discourse over 20 years from a comparative perspective, as this best reflects the wider conversations in circulation which influence the reception and evaluation of interactivity. Longitudinal analysis gathers a wide range of perspectives and a variety of technologies and contexts, challenging some technologically determinist narratives on interactivity. Discourse data also avoid issues with subjective self-reporting in user studies noted in previous research (Koolstra and Bos, 2009).

\section{0 years of interactivity discourse}

In order to capture the range of meanings in circulation over time both in quantitative and qualitative terms, this study subjects two samples of public discourse to a content and discourse analysis. Content analysis is appropriate for large number of texts in order to make broad inferences about representation (Deacon et al., 2010). Its methodical and systematic features also provide the reliability and validity for a discourse analysis to examine the carriers of meanings in circulation in more detail (Dahlgren, 2013). This is particularly useful for problematic concepts like interactivity.

The first sample, used in an extensive analysis of public discourse on interactivity in Ireland (Barry, 2012c), comprises 895 articles from Irish print media from 1995 to $2009 .{ }^{1}$ The second comprises a comparative sample of 224 articles from international print media in 2014. ${ }^{2}$ Articles were sourced from LexisNexis using a keyword search for 'interactivity' and 'interactive' in body text. The variety of commentary across both datasets on evolving technologies and their uses provides a rich source of discourse on two decades of interactivity the early Web, convergence of media industries, digitisation of creative industries, arrival of smartphones, social media, the impact of mobile and ubiquitous computing and more. As the first dataset sources Irish public discourses, some caution could be taken applying the findings in a wider context. However, previous studies have found that Ireland's semi-peripheral position produces significant in-flows of international discourse (Barry, 2012b), demonstrated in the volume of internationally syndicated material in Irish media, selected deliberately for this study. Furthermore, researchers have called for more interactivity studies from countries outside the United States (Larsson, 2012).

Both samples were subjected to detailed content analysis where each article was coded for 21 variables with multiple values such as topic, relevance, quotes, themes and so on. As there is no generally accepted formula for establishing validity for discourse analysis text choices, the quantitative findings are used to identify articles deemed representative and suitable for discourse analysis. The articles for this study were chosen according to frequency of keywords, relevance, statistical representation of variables, intertextual discourse material and so on. Discourse analysis then involves a detailed inspection of the language, references, genre of writing, use of metaphor and so on, with a particular focus on recurring themes in discourse.

\section{Describing the discourses on interactivity}

Many representations of interactivity arise in both samples, but this study focuses in particular on themes or 'modes' of interactivity, reflecting discourses on its meaning, 


\begin{tabular}{|l|c|c|}
\hline \multicolumn{1}{|c|}{ MODE OF INTERACTIVITY } & $\mathbf{1 9 9 5 - 2 0 0 9}$ & $\mathbf{2 0 1 4}$ \\
\hline Empowerment & $22 \%$ & $30 \%$ \\
\hline Commercial & $20 \%$ & $22 \%$ \\
\hline Pedagogical & $18 \%$ & $9 \%$ \\
\hline Aesthetic & $11 \%$ & $19 \%$ \\
\hline Ludological & $9 \%$ & $11 \%$ \\
\hline
\end{tabular}

Figure I. Frequency of modes of interactivity in both samples.

along with 'configurations', which describe the technological context. The mode of interactivity is identified in discourse through 'construals' (after Fairclough, 2009) emerging from genre, vocabulary, metaphor, use of quotation and so on. Each article is coded for up to three modes and most display at least two, demonstrating the potential for multiple-layered interactivities in a single event, as noted in the literature. Empowerment, the focus of this study, is one mode identified in discourse, where interactivity is said to 'enable' action, 'allow' access or 'offer' possibilities, choices or opportunities in communication. Other discourse modes include Aesthetic (emphasising sensory aspects), Ludological (play or game-like), Commercial (revenue generating) and Pedagogical (teaching/learning-related) interactivity, outlined in detail elsewhere (Barry, 2012a, 2012c, 2014). 'Configuration' refers to the specific technology in use. The early sample found 24 separate configurations, while the 2014 sample identified 16 configurations (both record less than two instances of a configuration as 'other'), reflecting the changing technological contexts of both samples.

\section{Content analysis findings}

Empowerment is the most frequent 'mode' of interactivity across both datasets (see Figure 1), accounting for over one-fifth of the early discourses, rising to almost a third of discourses in 2014.

Other modes also change over time: the Aesthetic mode rises $8 \%$ and Commercial and Ludological modes by $2 \%$. This is most likely due to their association with (and growth in references to) social media and games in the intervening years. The Pedagogical mode declined by $9 \%$, possibly due to reduced coverage of 'e-Learning' and educational software. Several variables could explain these trends, but most pertinent for this analysis is the 'configuration' associated with interactivity.

From 1995 to 2009, the configurations most associated with interactivity are Websites, $T V$, Exhibits and Software, with 'interactive' $C D$-ROMs a notable technology of the time, now defunct. By 2014, Apps are the most frequent configuration associated with interactivity, while Social media and Games have increased significantly. The newcomers are Smartphones, eBooks and iPads, reflecting a changed media landscape (see Figure 2).

The risers and fallers merely reflect (like the literature) how interactivity is often associated with the prominent new technologies of the age. The more valuable findings are those configurations maintaining a consistent association with interactivity over 


\begin{tabular}{|c|c|c|}
\hline CONFIGURATION & $1995-2009$ & 2014 \\
\hline Website & $17 \%$ & $8 \%$ \\
\hline TV & $14 \%$ & $7 \%$ \\
\hline Exhibit & $11 \%$ & $9 \%$ \\
\hline Software (desktop) & $9 \%$ & (see Other 2014) \\
\hline Title (of entity/company) & $8 \%$ & (see Other 2014) \\
\hline E-learning applications & $5 \%$ & $2 \%$ \\
\hline General digital - unspecific & $5 \%$ & $9 \%$ \\
\hline 'Interactive' CD/DVD-ROM & $4 \%$ & N/A \\
\hline Museum & $3 \%$ & $7 \%$ \\
\hline Game & $2.5 \%$ & $8 \%$ \\
\hline Touchscreen/kiosk/whiteboard & $2 \%$ & (see Other 2014) \\
\hline Social Media & $1 \%$ & $8 \%$ \\
\hline Ad & $1 \%$ & $3 \%$ \\
\hline Other 95-09 (Inc. Apps) & $<1 \%$ & N/A \\
\hline App & (see Other 95-09) & $11 \%$ \\
\hline Smartphone & N/A & $4 \%$ \\
\hline eBook & N/A & $4 \%$ \\
\hline iPad/Tablet & N/A & $2 \%$ \\
\hline $\begin{array}{l}\text { Other } 2014 \text { [inc. Title, Touchscreen, } \\
\text { Software etc.] }\end{array}$ & N/A & $4 \%$ \\
\hline (Non digital) & $(11 \%)$ & $(13 \%)$ \\
\hline
\end{tabular}

Figure 2. Most frequent configurations associated with interactivity in both samples.

time, such as Exhibits, reaffirming the important and complex relationship between museums or galleries and interactive technologies (Barry, 2014). The rise of 'other' configurations is also notable - the number of technologies referred to less than twice is on the increase. Particular attention is drawn, however, to the growth of General unspecific digital communications. It suggests that interactivity is a more generic descriptive term for digital experiences in 2014.

Empowerment is associated with more configurations than any other mode. By comparing 'configuration' with 'mode', we see that technologies most associated with interactivity in the earlier discourses - Websites, $C D-R O M s$, TV - are also most associated with Empowerment (see 1995-2009 in Figure 3). There is also a correspondence between Empowerment and the configurations on the increase, such as Games and General digital applications. This trend is more pronounced among the most frequent configurations of 2014 where $72 \%$ of the General applications are associated with Empowerment. The most frequent newcomers are also most frequently coded as Empowerment $-70 \%$ of Apps and $82 \%$ of Social media references. However, other frequent configurations in 2014 like Games and Websites tend to be associated with other modes of interactivity. 


\begin{tabular}{|c|c|c|}
\hline CONFIGURATION & $\begin{array}{l}\frac{1995-2009}{\text { empowerment }} \\
-(\% \text { overall })\end{array}$ & $\begin{array}{l}\frac{2014}{\% \text { empowerment }} \\
-(\% \text { overall })\end{array}$ \\
\hline Website & $54 \%-(17 \%)$ & $47 \%-(9 \%)$ \\
\hline TV & $42 \%-(14 \%)$ & $42 \%-(7 \%)$ \\
\hline Exhibit & $32 \%-(11 \%)$ & $50 \%-(9 \%)$ \\
\hline Software (desktop) & $38 \%-(9 \%)$ & (see Other 2014) \\
\hline Title (of entity/company) & $9 \%-(8 \%)$ & (see Other 2014) \\
\hline E-learning applications & $26 \%-(5 \%)$ & $0 \%-(2 \%)$ \\
\hline General digital - unspecific & $47 \%-(5 \%)$ & $72 \%-(9 \%)$ \\
\hline 'Interactive' CD/DVD-ROM & $49 \%-(4 \%)$ & $\mathrm{N} / \mathrm{A}$ \\
\hline Museum & $19 \%-(3 \%)$ & $27 \%-(7 \%)$ \\
\hline Game & $43 \%-(2.5 \%)$ & $39 \%-(8 \%)$ \\
\hline Touchscreen/kiosk/whiteboard & $37 \%-(2 \%)$ & (see Other 2014) \\
\hline Social Media & $1 \%-(1 \%)$ & $82 \%-(8 \%)$ \\
\hline Ad & $35 \%-(1 \%)$ & $50 \%-(3 \%)$ \\
\hline Other 95-09 (Inc. Apps) & $4 \%-(<1 \%)$ & N/A \\
\hline App & (see Other 95-09) & $70 \%-(11 \%)$ \\
\hline Smartphone & $\mathrm{N} / \mathrm{A}$ & $79 \%-(4 \%)$ \\
\hline eBook & N/A & $37 \%-(4 \%)$ \\
\hline iPad/Tablet & N/A & $50 \%-(2 \%)$ \\
\hline $\begin{array}{l}\text { Other } 2014 \text { [inc. Title, } \\
\text { Touchscreen, Software etc.] }\end{array}$ & N/A & $50 \%-(4 \%)$ \\
\hline
\end{tabular}

Figure 3. Comparison of the most frequent configurations coded with the 'Empowerment' mode of interactivity in both samples (and with frequency of overall).

Space does not permit further quantitative analysis but these findings illustrate the dominance of the Empowerment discourse, its association with a wide variety of configurations and with the increasingly generic use of interactivity in descriptions of all digital media.

\section{Interactivity and empowerment in the literature}

Fiske (2011) suggests that empowerment occurs through both the processes and outcomes of popular communication. Users are empowered by the development of the 'interactive' mode in computing which allows operators to intervene and view processes, changing the relationship between human and machine (Jensen, 1998; Suchman, 1987). Interactivity tips the balance of power as a characteristic of technologies, processes and the content they facilitate. But Manovich (2001) asserts that the cognitive power of interactivity, which allows users to 'change the work', is where ideological tropes such as 
'empowerment' emerge. Users are 'empowered' to choose paths, take their own meanings, contribute content and register pleasure or dissatisfaction with an experience. When user actions are tied to intentions, this feeling of empowerment experienced is associated with 'agency' (Murray, 1998), described as an essential property of interactivity in narrative games (Mateas, 2001).

Interactivity can empower an electorate in material or symbolic ways, by facilitating a change in (their perception of) their relationship to politicians (Bucy and Gregson, 2001). Similar empowering and disruptive potential drives anarchic and civic engagement perspectives on interactivity (Stromer-Galley, 2004). Even the physical structure of the Internet creates a sense of empowerment, observed in the collective agency and collaboration it enables (Flanagin et al., 2010). Indeed, this capacity for empowerment becomes 'a condition of possibility for participation' (Jenkins and Carpentier, 2013: 274).

Yet, other participants in these processes are similarly and separately empowered. Science museums use the 'ideological trope' of empowerment associated with interactivity to bridge the perceived gulf between science and society (Barry, 2001). The 'fetish' for interactivity is an invaluable branding tool, aligning museums with potential transformation (Hughes, 2001). Lahey (2014) finds a 'rhetoric of empowerment' across a spectrum of digital media applications from genuinely enriched user experiences to deliberate control of audiences by media industries 'masquerading' as user-generated content (UGC). Such audience interactivity is far from democratizing (Couldry, 2012). Thus, the empowerment potential of interactivity permeates discourse on technologies, processes and perceptions of outcomes for all participants. The value of interactivity is its ability to transcend the limits of these features but this in effect generates its multifaceted and contested nature. Without a clear understanding of its empowering features or how it may be differentiated from related concepts of agency and participation, it remains exposed to hype.

\section{Interactivity and empowerment - a discourse analysis}

This analysis explores three moments in the two decades of public discourse on interactivity that illustrate its relationship with empowerment through selected representative articles: first, a 1998 report on new interactive digital technologies displaying empowerment through access and contextual novelty; next, reports from 2001 on online news coverage of $9 / 11$ and the empowering interactivity of the web; and finally, a growing literacy around the concept in 2014 found in more complex contexts of use.

\section{Potential unleashed}

In 1998, interactivity is central to the new digital technologies appearing in such diverse contexts as science, entertainment, education and business. The first analysis selects a syndicated article from the Guardian (Guardian Service, 1998), where the keywords appear 14 times along with the most frequent configurations across a variety of contexts, following a 'diffusion of innovation' model (see Rogers, 1995) in its expository writing style. It focuses on discourses around interactivity in legal proceedings, where a new 
virtual reality (VR) system developed by Australian police helps 'walk witnesses and juries through the scene of a crime' during criminal trials:

Resembling the technology in the film Blade Runner that allowed Harrison Ford to navigate a flat via a photo, the Queensland Police's Interactive Crime Scene Recording system will be used for the first time in a murder trial pending before Brisbane's Supreme Court

The concept of interactivity figures routinely in discourses where technology emerges as a solution to how people adapt to living in a technological society (Barry, 2001). Here, interactivity 'allows' navigation implying that the technology (and its context) provides the potential for action and also the permission to act. The metaphor - Blade Runner (Scott, 1982) - is meant to guide readers through how the system works, lending it a futuristic feel, where technology 'enables' the detection of crime and pursuit of justice. However, Blade Runner set in the Los Angeles of 2019, is dense with more complex readings, offering a dystopian vision of a technology-soaked urban world, exposing the dark side of technological progress (Bruno, 1990). In the article, interactivity empowers 'Harrison Ford', whereas in the film, his character 'Deckard' uses technology to 'retire' replicants, implying empowerment beyond mere access. The Esper photo analysis machine that 'allowed' such navigation has the capacity for infinite zoom and focus, certainly an attractive quality for forensic science. Furthermore, photographs have legal document status in the film and play a crucial role in challenging memory and reality, deciding the fate of key characters. By invoking Blade Runner in a discussion of technology, interactivity is linked with both empowerment and 'threat', a pervasive duality in new media discourse (Poster, 2002).

It was the jury in the courtroom with the joystick. The system debuted at a trial, concerning the brutal murder of a Japanese backpacker. Intertextual analysis reveals that public concern about the impact of this crime on the Queensland tourist industry created intense political pressure to appear speedy and decisive in the criminal investigation and prosecution - the use of technology was central (Mason, 2006). The focus on interactive technology in the case appears to empower users of the system but also society in general against the wider ramifications of crime. Interactivity empowers an institution of the state in the exercise of its authority, which in turn endorses the technology. The question of who ultimately holds power, beyond the communicative event of examining crime scenes during trials, is not addressed.

The article displays a style of technology reporting found frequently in the earlier discourses, which methodically explains how a technology works. This 'procedural' and 'hortatory' writing style (Van Leeuwen, 2008:346) demystifies the system, described it like 'being inside a photographic cylinder' allowing a variety of actions - 'left to right', 'zoom', 'jump' and so on. Ultimately, it gives 'you [the user] the sensation of walking through the crime scene'. Ease of use and transparency of operation are basic empowering aspects of technology, but its interactivity further empowers users by turning them into authorised crime scene investigators. And another icon of popular culture helps readers understand the interface: 
To make navigation ... easier, [images] are incorporated into an interactive document resembling a Cluedo board; on one side is a map of the crime scene... Click on a hotspot and a photo of the evidence appears...

Interactivity turns evidence into a game, making a complex, open-ended trial into a closed puzzle with a correct solution. This implies potential for strategic action and fun, within the constraints of game rules, introducing a minor ludological discourse of interactivity. The jury are now players in a game, and interactivity empowers them to solve the crime and win.

Empowering society. Further intertextual analysis shows that 2 weeks after publication, a member of the Irish Parliament asked the Minister for Justice whether 'the Queensland police's interactive crime scene recording system which will be used for the first time in a murder trial in Brisbane Supreme court [sic]...' would be introduced in Ireland. ${ }^{3}$ The verbatim description suggests direct quotation from the article, illustrating how discourse travels directly between legal, media and political institutions.

Despite the strength of discourse on empowerment of participants and civil society, the potential of interactivity remains somewhat 'leashed'. The analysis raises questions about the appropriate use of interactive technology in legal systems. Constraint on their use, however, depends on individual, corporate and political attitudes to specific implementations, which further studies should address.

\section{Potential challenged}

In 2001, offline print media evaluated how online news (a relatively new arrival) reacted to the 9/11 attacks in the United States. The scale of the event and global demand for instant information posed a challenge to all newsrooms, as outlined in two articles (Gibson, 2001; Irish Times, 2001). Technical issues dominate the discourse in assessing the impact, literally, as servers for many major news websites located in Manhattan were damaged. Also, intense traffic 'broke all records' causing websites to 'topple' as one quoted editor unfortunately put it. However, online media are seen to have risen to a challenge, providing coverage and communication with audiences in ways broadcast and print media simply could not:

Such interactivity represents [an] aspect of the Internet's enrichment of the media environment... the web channelled a phenomenal outpouring of humanity last week.

This 'channelling' represents a level of empowerment beyond mere access and action. It facilitates the collective expression of an entire community in a unique way. Online news is presented as facilitator of production and reception:

The web is ... more interactive than TV and complements it well ... readers were a prime source of information ...

Thus, interactivity marks the difference between new media and old, by empowering users to contribute content, not as an addition to other streams but as a 'prime source', a 
significant journalistic admission. Content is produced by the masses for the masses in response to an outpouring of emotion, illustrating how interactivity also inverts traditional sender/message/receiver relationships. Online news itself is also empowered, and some collegiality emerges from the devastation of the event but also from the interactive communication:

interactive elements, audio and video, were extremely popular ... there was an unusual feeling of cooperation between broadcasters and sites ...

The empowerment of the interactive Web is bound up with the changing nature of journalism and news production. Indeed, there is an extra responsibility and workload for media professionals in dealing with interactivity. Understanding how empowerment and interactivity operate at different levels in both individual and mass communication phenomena can clarify the role of news media within an enriched technological environment. Ultimately, the discourses indicate that interactive media display their difference and prove their worth through the reach of their communication potential.

\section{Potential achieved?}

By 2014, Empowerment discourses appear even more frequently but are increasingly associated with generic configurations. Four articles illustrate this use of interactivity as general digital descriptor and reflect a shift in reporting style towards assuming a literate readership. First, according to a headline in the Sydney Herald, the top trend in family holidays is 'interactivity' (Spicer, 2014). There are no descriptions of how specific technologies work or why interactivity is important. Instead, a valuable user demographic gives an endorsement:

Airlines, hotels, and attractions are scrambling to improve their connectivity, because miniconsumers demand it ... "Mum, I really don't care what hotel we stay in, as long as it's got free Wi-Fi!

This discourse describes basic empowerment offered by access on the road. The article briefly acknowledges some applications facilitated by Wi-Fi (e.g. touchscreens, apps and games), assuming users are equipped to interact in the new mobile media paradigm. Previous studies found a small but significant Hula Hoop discourse, where children recognise interactivity almost innately, before or even without adults ever doing so (Barry, 2012c). Wi-Fi interactivity empowers such 'mini-consumers' with autonomy, while the travel business competes for their custom, revealing a Commercial mode within. The author even notes that interactivity helps maintain 'sanity' on holiday, a kind of psychological empowerment beyond communication.

Next is a rare example in 2014 of a guide to new technology. However, the article (Carter, 2014) lacks the metaphors found in the earlier sample and is notable for its critical tone on Google Glass, which is '... tricky to set up ... annoying ...' and too demanding. The article attempts balance in presenting the variety of apps, its 'wearable' design and so on but concludes with a devastating punch: 'If this was an Apple device, it wouldn't have seen the light of day ...' This association between Apple and 'cutting-edge' technology 
was also found in earlier discourses (Barry, 2012c). The focus on brands is further emphasised by quoting a 'global brand analyst':

I don't want Google Glass ... I want smart, contextual, helpful data and interactivity in my eyeballs. We see this 'data in the wild' as an inevitable and imminent part of everyday life.

The analyst disassociates interactivity from hyped new technologies. It is no longer a characteristic of a specific configuration but of digital communication - and data - in general. Brands that misunderstand its 'wild' empowering features may damage themselves in the process. This 'appropriate' interactivity is recent to discourse and echoed in an article describing a new mobile phone that has 'scaled back on all the usual interactivity' (Herald Sun, 2014). The developer proudly states 'it can receive calls and it can make calls', thus empowering users by rejecting interactivity altogether.

Next, a new TV show allows viewers to vote for singers as hit or miss via smartphone, taking 'interactivity to a whole new level', according to the producer (Chater, 2014). Again, the article gives no description of the app or how it works. The audience is framed as literate in a new communication paradigm of 'second screening', where UGC is a form of empowerment. ${ }^{4}$ The producer's endorsement reflects how UGC is frequently offered as 'media produced gifts to be shared' but which are exploited for the profit of the platform owners (see Jenkins, Ford and Green, 2013). It echoes Lahey's (2014) rhetoric of empowerment that keeps audiences inside a walled garden. Thus, a somewhat limited empowerment diverts attention from perhaps other significantly empowered or disempowered participants within hidden layers of commercial interactivity in these or further connected events.

The final discourse example (Ellery, 2014) describes 'the most interactive Web portal ever', where users share information on soldiers who served in World War I:

An unprecedented level of interactivity ... allows members of the public to log on and upload photographs, additional information, anecdotes and family history.

The familiar evaluative vocabulary of 'most interactive ... ever' echoes the rhetoric of consumer empowerment associated with TV producers. But this UGC creates a participatory audience that, crucially, retains control of information and arguably gains more from collaborative efforts:

My grandfather was ... quite silent on his experiences ... now I'll be able to research my grandfather ... and there's an inheritance [of knowledge] for my own children.

The ability to contribute to community building and continuity of memory achieves a kind of empowerment absent from the UGC associated with commercial TV. Such 'digital memorial' websites use interactivity to allow users put pieces of a puzzle together, linking previously unconnected data and communities and creating a new resource, perhaps even a new history for future generations. ${ }^{5}$ The outcomes are not just informative but performative, building a shared public memory with myriad benefits for the communities involved. 


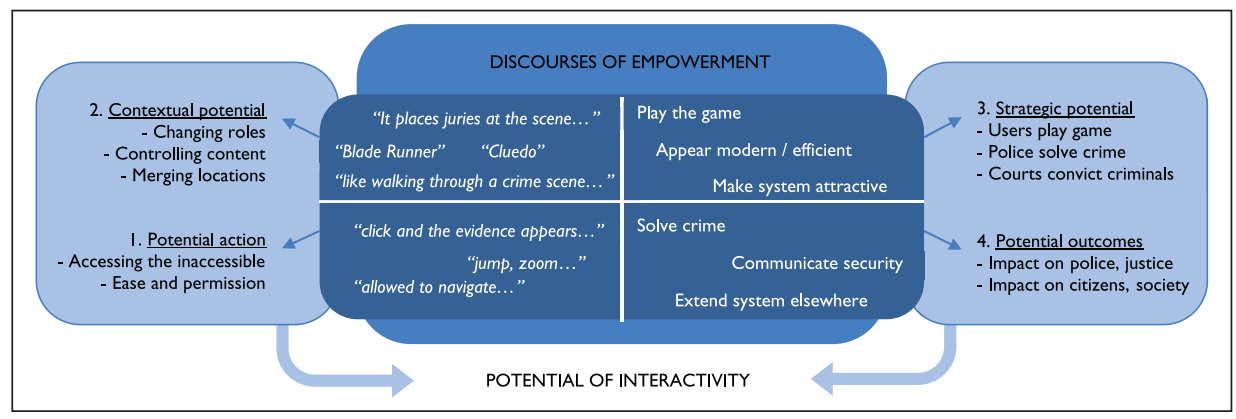

Figure 4. Identifying how public discourse links interactivity with empowerment.

\section{Discussion}

This study shows how interactivity has long been associated with a spectrum of empowerment across a changing media landscape. In 1998, the discourse around new software associates interactivity with access, permission and investigative powers and potential for wider social effects. In 2001, discourses about interactivity of the Web amplify empowerment through descriptions of mass communication and channelling of emotion. By 2014, discourses on mobile access, 'data in the wild' and 'second screening' accentuate the contextual flexibility of interactivity, allowing multiple actions and relationships, while digital memorials offer channelling effects into the future.

Each example of interactivity reflects the different technologies of its time, yet the discourse consistently relates to similar features of communication. First, interactivity 'allows' potential actions; next, it creates contextual potential to alter the content and participant roles; then it facilitates strategies of communication - which may differ between participants - such as learning, sensory experiences or social connection. Finally, interactivity offers potential for different outcomes in communication, including emotional, political or commemorative implications beyond the immediate.

\section{Modelling interactivity and empowerment}

The discourse analysis links interactivity to empowerment through the actions, context, strategies and outcomes of interactive communications. For example, the analysis of the crime scene software locates the four elements in the language around that configuration (see Figure 4). First, interactivity empowers users through actions (click, jump, and zoom) giving access to content or locations. Next, it empowers through context (walk through the scene as investigator), then engagement in strategies with added value (play the game) and finally, the potential outcomes of interactivity point to empowerment (solve crime and empower society).

These four elements feature in all interactive communications but their potential for empowerment differs between individual events. The analysis of discourses around interactivity in online news after 9/11 attacks shows similar potential in actions, contexts and strategies but reveals a fuller expression of empowerment in actual outcomes. By 


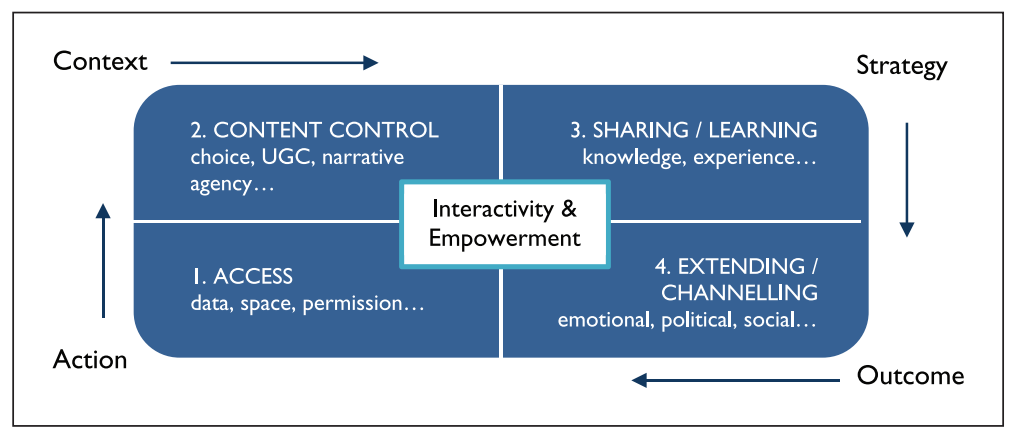

Figure 5. Modelling the empowerment of interactivity with four elements of communication.

2014, interactivity is associated with more 'unspecific' and possibly layered configurations. But whether it is 'mobile access', 'data in the wild' or 'second screening', the same aspects of interactivity drive empowerment. Discourses on 'mobile access' and 'data in the wild' focus on access and content control, offering a spectrum of actions and contextual potential, while 'data in the wild' and 'second screening' add strategic potential through sharing capabilities. Digital memorials offer outcomes that reflect the channelling effects of the Web. Mapping the four elements of communication onto aspects of empowerment identified in public discourse produces a general model to help understand how interactivity and empowerment are linked (See Figure 5).

A contextually flexible model. This model reflects the variety of contexts arising across two decades of interactivity, yet is flexible enough for use with future configurations. In the past, interactivity was strongly associated with specific technologies like the Web, but recent discourses acknowledge its general potential for digital communications. Older discourses rely on procedural and metaphorical techniques to explain interactive technologies to novice audiences. But recent discourses recognise a more literate public, demanding interactivity, challenging hyped technologies that do not deliver and recognising inappropriate interactivity. Thus, the value of interactivity goes beyond the potential for action and context to the strategies and outcomes it offers for communication.

The model offers a novel way to explore interactivity, either externally for the purposes of interaction design or internally for evaluating production. Using such a model to create specifications and constraints for digital media design places empowerment at the centre of the production process with results more likely to produce appropriate interactivity or match expectations. From an evaluation perspective, the model can be used to explore how interactivity operates and empowerment is facilitated. For example, if interactivity transforms the passive viewer to an active user (Lister et al., 2003), according to this model, the transformation emerges from its contextual potential. However, the extent of potential empowerment is measured in the strategies and outcomes that can be explored for a range of different participants with diverse expectations and outcomes. The model also caters for the contextually flexible and multilayered plural interactivities increasingly found in communication events like 'second screening'. 
Forms of empowerment through interactivity. Richards (2006) calls for further research into forms of power facilitated by different modes of interactivity. This model provides a lens through which such questions can be examined, for example: who permits the access that interactivity enables? The model locates the answer in the potential actions and context of communication, that is, the Australian court's implicit approval of 'interactive' software, its uses and outcomes, suggests permission from the legal, constitutional and contextual frameworks in which it operates. Meanwhile, the 'free Wi-Fi', demanded by children, is permitted by parents, facilitated by Internet service providers (ISPs), device manufacturers, app producers and so on. Thus, the model reveals the chain of contributors to communication.

By focusing on the context, participants and strategies employed, we can also see who is disempowered by interactivity. The second-screening example reveals invisible participants - telecoms operators, ISPs, broadcasters, TV producers, social media, supporters - bringing individual actions and strategies to the interactive chain. Assessing the outcomes for each - winning, laughing, earning - provides clues to relative empowerment. This provokes further questions on the value of empowerment for participants, the impact of different values or strategies on outcomes and the relationship between context and potential outcomes. The Google Glass example illustrates what happens when technology falls short of expectations. Although the discourse eventually released interactivity from this configuration into the 'wild' with unlimited potential, the model provides a structure for examining such idealised discourses and the communities promoting them.

Multi-modal interactivity. The model is useful for examining overlaps between different modes of interactivity. As noted, the discourses were coded for several modes of interactivity in the same event, evidence (in discourse at least) of the plural and generative perspectives outlined in theory. Previous research has shown that a limited empowerment effect is designed by artists into the actions and strategies open to audiences of interactive artworks (Barry, 2014). But by limiting the context of communication and potential outcomes for users, the artist asserts control over the potential empowerment of artworks, bringing Aesthetic interactivity to the fore. Thus, like software interface layers, interaction designers can 'bring forward' or 'send to back' the layered modes of interactivity. The model can be used to evaluate these different layers and design for them.

Interactivity theory and agency. This model can build on existing interactivity theory but requires a reorientation of perspective. The 'technology' and 'context' elements of Kiousis' (2002) explication of interactivity are reflected in the model. However, the third element of 'perception' is a subjective measure of participants' known interactivities and can only be evaluated via user studies, where levels of interactivity 'probably ... can vary across technology, communication settings, and individuals' perceptions' (Kiousis, 2002: 277), thus each study producing further subjective definitions rather than consensus. This model instead focuses on strategy and outcomes to objectively assess potential and actualised interactivity. It can also be used to assess hidden or layered interactivities and those other unknown participants, which could further advance interactivity theory. Rather than seeking to achieve consensus with a single all-encompassing definition, the model recognises that interactivity empowers different participants at various levels. By 
identifying these different layers of interactivity and empowerment, it could locate 'agency' in applications, if agency requires actions to align with strategy (Mateas, 2001). Further research could examine where agency and interactivity meet or diverge and whether agency is best served when other modes of interactivity (Ludological, Aesthetic) combine with Empowerment.

\section{Conclusion}

This study presents a different way of theorising interactivity by examining how we talk about it. Findings from a unique long ranging study of public discourses reveal the dominant discourses on interactivity and common aspects of its meaning across a more wideranging set of contexts and experiences than previous research. This approach avoids relying on specific configurations or subjective definitions that have been contentious in the literature. It identifies distinct 'modes' of interactivity in discourse where the dominant mode is Empowerment, despite changes in technologies and media use over time. It also reveals a growing association between interactivity and general media experiences in discourse rather than with specific technologies. Discourse analysis produces valuable research material, drawing in wider aspects of context and strategy in communication than direct interrogation of users or interactive events. This delivers a more contextually flexible approach to understanding interactivity with pragmatic use for digital practitioners.

Furthermore, the analysis identifies discourse communities that play an important role in circulating meaning. They show how texts can become sites of struggle with differing ideologies competing for dominance, evident in both public and academic discourse. Further studies could examine how children, brand analysts, politicians, media producers or media and HCI research communities talk about interactivity. The two samples of Irish and international public discourses did not produce significant differences in findings attributable to location, but future studies could examine if cultural differences do exist in interactivity discourses. Comparative research from other states could help ascertain if interactivity discourses are local, global or influenced by particular geocultural perspectives.

This study makes an original contribution to research in a new model of interactivity and empowerment. This maps the four elements of interactive communication - action, context, strategy and outcomes - onto the four realms of empowerment found in the discourse: access, content control, sharing/learning and channelling. These layered and contextually flexible features of interactivity can be recognised in all interactive communications, from design through to operation, and their associated levels of empowerment measured. Thus, the model benefits digital media research and practice even in complex multilayered paradigms. It offers a path beyond the push and pull of interfaces, to the layers of interactivity within and perhaps rippling beyond, towards producing more effective interactivity that we can talk about and understand.

\section{Funding}

This work was supported by the Irish Research Council under the Government of Ireland Postdoctoral Fellowship Scheme. Gavin Doherty would also like to acknowledge the support of his research in part by Science Foundation Ireland grants 10/CE/I1855 and 12/CE/I2267. 


\section{Notes}

1. The Irish Times was selected as the source for articles having reliable and complete coverage for the entire sample period (1994-2009). As the 'paper of record' with extensive international coverage and significant readership within the business, cultural and political community (see www.jnrs.ie), it is a valid source for research.

2. The international sample was sourced from 60 different English-language titles across 18 geographic areas.

3. According to 'Written Answers - Garda Technology', Dáil Eireann Debates 494 (5). Indeed UK and Irish police forces visited Australia in 1998 to see this approach to forensic technology in action (see Needham, 1998).

4. In all, $3 \%$ of articles in 2014 required double coding for configuration in a single communication event due to references to 'second screening' activities, for example, coding for 'TV' and 'smartphone'.

5. See also Lives of the First World War, developed by the Imperial War Museum, UK. Available at: https://livesofthefirstworldwar.org/

\section{References}

Aarseth E (1997) Cybertext: Perspectives on Ergodic Literature. Baltimore, MD: Johns Hopkins University Press.

Barry A (2001) Political Machines: Governing a Technological Society. London \& New York. Athlone Press.

Barry M (2012a) Fifteen years of talk: newspaper discourses on Ireland's interactive science museum. Irish Communications Review 13: 116-132.

Barry M (2012b) Notes from the semi-periphery: Ireland's press coverage of the developing world and the value of small state studies in international communications research. International Communication Gazette 74(2): 124-144.

Barry M (2012c) The age of interactivity: an historical analysis of discourses around interactivity in Ireland 1995-2009. PhD Thesis, Dublin City University, Dublin.

Barry M (2014) Please do touch: discourses on aesthetic interactivity in the exhibition space. Participations: Journal of Audience and Reception Studies 11(1): 216-236.

Birch H and Weitcamp E (2010) Podologues: conversations created by science podcasts. New Media \& Society 12(6): 889-909.

Bruno G (1990) Ramble city: postmodernism and Blade Runner. In: Kuhn A (ed.) Alien Zone: Cultural Theory and Contemporary Science Fiction Cinema. London: Verso, pp. $183-195$.

Bucy EP (2004) Interactivity in society: locating an elusive concept. The Information Society 20(5): 373-383.

Bucy EP and Gregson KS (2001) Media participation: a legitimizing mechanism of mass democracy. New Media \& Society 3(3): 357-380.

Canter L (2013) The interactive spectrum: the use of social media in UK regional newspapers. Convergence 19(4): 472-495.

Carter J (2014) Looking for trouble. South China Morning Post, 24 October. [Available at http:// www.scmp.com/lifestyle/article/1622987/why-google-glass-turning-consumers]

Chater D (2014) Viewing guide. The Times, 1 August. [Available on LexisNexis]

Couldry N (2012) Media, Society, World: Social Theory and Digital Media Practice. Cambridge: Polity Press.

Cover R (2006) Audience inter/active: interactive media, narrative control and reconceiving audience history. New Media \& Society 8(1): 139-158. 
Dahlgren P (2013) The Political Web: Media, Participation and Alternative Democracy. Basingstoke: Palgrave Macmillan.

Deacon D, Pickering M, Golding P, et al. (2010) Researching Communications, 2nd Edition, London: Bloomsbury Academic

Downes EJ and McMillan S (2000) Defining interactivity: a qualitative identification of key dimensions. New Media \& Society 2(2): 157-179.

Ellery D (2014) Memories, stories of WWI brought to life. Canberra Times, 29 October. [Available on LexisNexis]

Fairclough N (2009) A dialectical-relational approach to critical discourse analysis in social research. In: Wodak R and Meyer M (eds) Methods of Critical Discourse Analysis. London: SAGE, pp. 162-186.

Fiske J (2011) Introduction to Communication Studies. 3rd ed. Abingdon: Routledge.

Flanagin AJ, Flanagin C and Flanagin J (2010) Technical code and social construction of the internet. New Media \& Society 12(2): 179-196.

Gibson O (2001) Online editors pushed to the limit. Irish Times, 24 September (syndicated version of, When the web came of age. The Guardian, 17 September). [Available at http://www. theguardian.com/media/2001/sep/17/mondaymediasection.september1120017]

Guardian Service (1998) Potential of virtual reality is about to be unleashed. Irish Times, 25 September. [Available at http://www.irishtimes.com/business/potential-of-virtual-reality-isabout-to-be-unleashed-1.197146]

Heath C, vom Lehn D and Osborne J (2005) Interaction and interactives: collaboration and participation with computer-based exhibits. Public Understanding of Science 14: 91-101.

Heeter C (1989) Implications of new interactive technologies for conceptualizing communication. In: Salvaggio JL and Bryant J (eds) Media Use in the Information Age: Emerging Patterns of Adoption and Computer Use. Lawrence Erlbaum Associates, pp. 217-235.

Herald Sun (2014) Easy phone goes back to basics. Herald Sun, 25 August. [Available at http:// www.heraldsun.com.au/leader/south-east/news-story/1ba96c9ffdfe3ac8d7a3ed48abc85af0]

Holmes S (2004) 'But this time you choose!': approaching the 'interactive' audience in reality TV. International Journal of Cultural Studies 7(2): 213-231.

Howarth D (2000) Discourse. Buckingham: Open University Press.

Hughes P (2001) Making science 'family fun': the fetish of the interactive exhibit. Museum Management and Curatorship 19(2): 175-185.

Huhtamo E (1999) Cybernation to interaction: a contribution to an archaeology of interactivity. In: Lunenfeld P (ed.) The Digital Dialectic: New Essays on New Media. Cambridge, MA: MIT Press, pp. 96-110.

Hujanen J and Pietikainen S (2004) Interactive uses of journalism: crossing between technological potential and young people's news-using practices. New Media \& Society 6(3): 383-401.

Irish Times (2001) Reporting terror on the net. Irish Times, 24 September. [Available at http:// www.irishtimes.com/news/reporting-terror-on-the-net-1.328719]

Jenkins H and Carpentier N (2013) Theorizing participatory intensities: a conversation about participation and politics. Convergence 19(3): 265-286.

Jenkins H, Ford S and Green J (2013) Spreadable Media: Creating Meaning and Value in a Networked Culture. New York, NY: New York University Press.

Jensen JF (1998) Interactivity: tracking a new concept in media and communications studies. Nordicom Review 19: 185-204.

Jensen KB (2013) Contexts, cultures and computers: the cultural contexts of mediated communications. In: Jensen KB (ed.) A Handbook of Media and Communication Research, Qualitative and Quantitative Methodologies. London: Routledge, pp. 171-190. 
Jensen KB (2005) Interactivity in the wild: an empirical study of 'interactivity' as understood in organizational practices. Nordicom Review 26(1): 3-30.

Jorgensen M and Phillips LJ (2002) Discourse Analysis as Theory and Method. London: SAGE.

Kiousis S (2002) Interactivity: a concept explication. New Media \& Society 4(3): 355-383.

Koolstra CM and Bos MJW (2009) The development of an instrument to determine different levels of interactivity. International Communication Gazette 71(5): 373-391.

Lahey M (2014) The framing of value: television, user-generated content, and interactive involvement. Convergence: 1-14 [Available at http://con.sagepub.com.elib.tcd.ie/content/early/201 4/12/24/1354856514563903.full] .

Larsson AO (2012) Interactivity on Swedish newspaper websites: what kind, how much and why? Convergence 18(2): 195-213.

Lim Y-K, Lee S-S and Lee K-Y (2009) Interactivity attributes: a new way of thinking and describing interactivity. In: ACM Proceedings of the 27th international conference on human factors in computing systems, CHI '09, Boston, MA, 4-9 April, pp. 105-108.

Lister M, Dovey J, Giddings S, et al. (2003) New Media: A Critical Introduction. 2nd Edition. London: Routledge.

McMillan SJ (2002) A four-part model of cyber-interactivity. New Media \& Society 4(2): 271-291.

McQuail D (2010) Mass Communication Theory. 6th ed. London: SAGE.

Manovich L (2001) The Language of New Media. Cambridge, MA: MIT Press.

Manovich L (2003) Introduction. In: Montfort N and Wardrip-Fruin N (eds) New Media Reader. Cambridge, MA: MIT Press, pp. 13-25.

Mason G (2006) Touring in safety. Current Issues in Criminal Justice 18(2): 185-201.

Mateas M (2001) A preliminary poetics for interactive drama and games. Digital Creativity 12(3): $140-152$.

Morley D (1993) Active audience theory: pendulums and pitfalls. Journal of Communication 43(4): 13-19.

Murray J (1998) Hamlet on the Holodeck. Cambridge, MA: MIT Press.

Nash K (2012) Modes of interactivity: analysing the webdoc. Media, Culture \& Society 34(2): $195-210$.

Needham K (1998) Keyboard cops. Sydney Morning Herald, 24 October.

Newhagen JE (2004) Interactivity, dynamic symbol processing and the emergence of content in human communication. The Information Society 20(5): 395-400.

Poster M (2002) Introduction to culture and new media. In: Lievrouw LA and Livingstone S (eds) Handbook of New Media - Social Shaping and Consequences of ICTs. London: SAGE, pp. $479-484$.

Quiring O (2009) What do users associate with 'interactivity'? A qualitative study on user schemata. New Media \& Society 11(6): 899-920.

Rafaeli S and Sudweeks F (1997) Networked interactivity. Journal of Computer-Mediated Communication 2. DOI:10.1111/j.1083-6101.1997.tb00201.x

Reinhard CD (2011) Studying the interpretive and physical aspects of interactivity: revisiting interactivity as a situated interplay of structures and agencies. Communications: The European Journal of Communication Research 36: 353-374.

Richards R (2006) Users, interactivity and generation. New Media \& Society 8(4): 531-550.

Rogers E (1995) Diffusion of Innovations. 4th ed. New York: Free Press.

Rogers Y, Sharp H and Preece J (2011) Interaction Design: Beyond Human-Computer Interaction. Chichester: John Wiley \& Sons.

Scott R (1982) Blade Runner. Los Angeles: Warner Home Video.

Shultz T (2000) Mass media and the concept of interactivity: an exploratory study of online forums and reader email. Media, Culture \& Society 22: 205-221. 
Sohn D and Choi SM (2013) Measuring expected interactivity: scale development and validation. New Media \& Society 16(5): 856-870.

Spicer T (2014) Top trends in family holidays. Sydney Morning Herald, 9 November. [Available at http://www.illawarramercury.com.au/story/2683211/exciting-new-trends-in-family-travel/]

Stromer-Galley J (2004) Interactivity-as-product and Interactivity-as-process. The Information Society 20(5): 391-394.

Suchman L (1987) Plans and Situated Actions: The Problem of Human-Machine Communication. Cambridge: Cambridge University Press.

Sundar SS (2004) Theorizing interactivity's effects. The Information Society 20(5): 385-389.

Van Leeuwen T (2008) News genres. In: Wodak R and Koller V (eds) The Handbook of Communication in the Public Sphere. New York: Walter de Gruyter, pp. 345-362.

Weber P (2014) Discussions in the comments section: factors influencing participation and interactivity in online newspapers' reader comments. New Media \& Society 16(6): 941-957.

Winston B (1998) Media, Technology and Society. Abingdon: Routledge.

Ziegele M, Breiner T and Quiring O (2014) What creates interactivity in online news discussions? An exploratory analysis of discussion factors in user comments on news items. Journal of Communication 64: 1111-1138.

\section{Author biographies}

Marguerite Barry is an Irish Research Council Postdoctoral Fellow at the School of Computer Science and Statistics at Trinity College Dublin. Her research interests are interactivity, digital media discourse, human computer interaction and digital media ethics.

Gavin Doherty is an Associate Professor in the School of Computer Science and Statistics at Trinity College Dublin. His research focuses on human-computer interaction within specific application areas, and he has led a range of interdisciplinary projects, particularly in the design of technologies for mental health. 